\title{
Syntactic Structure of Awgni Sentences Based on Form
}

\author{
Berhanu Asaye Agajie \\ Injibara College of Teacher Education, ETHIOPIA \\ Department of Language
}

Received: 25 April 2020 - Accepted: 8 July 2020 • Published Online: 20 July 2020

\begin{abstract}
The study attempted to assess syntactic structure of Awgni sentence based on form. Through purposive sampling, thirteen sentences were selected for analysis. Seven informants (three females and four males) were interviewed to crosscheck the relevance of the collected data. Results indicated that sentences in terms of their appearances, forming, constituents' grouping, or causal connection, the number and types of clause they hold were different. Every sentence structure shares syntactic representations that comprise Noun Phrases (NPs), Verb Phrases (VPs), Prepositional phrases (PPs), Adverbial Phrases (ADVPs) and Adjectival Phrases (APs). Sentences have both linear sequences of words; a hierarchical structure with phrases nested in phrases and resulted in dominance and precedence relationships. Finally, the study recommended a further research on some basic properties of Awgni syntax, grammatical functions and semantic roles.
\end{abstract}

Keywords: Awgni, representation, sentence, structure, syntactic.

\section{Introduction}

Awgni is the family of Southern Central Cushitic or Southern Agaw (Hetzron, 1966; Palmer, 1959) and as such, it belongs to the Cushitic branch of the Afro-Asiatic language subfamily. It is spoken in the Amhara Regional State, currently known as Awi Administrative Zone. The language can naturally be considered as free of the threat of endangerment. However, when conditions, like the speakers' attitude toward their language, the extensively increasing resettlement of non-Awgni speakers in the region, the multiply of commercial farms and urbanization are taken into account, it seems that the language is not reliably safe from the threat (Hetzron, 1969; Melakneh, 1991; Palmer, 1959; Tadese, 1988). According to Hetzron (1966), due to Semitic substratum, though slowly, is steadily being superseded many by Amharic. Tadesse (1984) also explains that as there is high acculturation process between Awi and Amhara and as tribalism in Awi is slow; there is the probability of Awgni extinction soon. On the other hand, Tadesse Tamrat (1988) and Haileluel (1991) point out that Awgni is by no means an endangered language. Recently, the language is written and rendering a service as a medium of mother-tongue education. Yet, it exhibits little or no written literature. Hence, its heritable cultural legacies are mostly existed in the memories of tradition bearers (Teferi, 2000; Yaregal, 2007).

(C) Authors. Terms and conditions of Creative Commons Attribution 4.0 International (CC BY 4.0) apply. Correspondence: Berhanu Asaye Agajie, Injibara College of Teacher Education, Department of Language, postal address 44 Injibara, ETHIOPIA. E-mail: berhanuas@gmail.com. 
- Sentences in terms of their forms, forming, constituents' combination, or causal relationship, the number and types of clause they contain were different.

- Each sentence structure shares syntactic representations (Ss) that include Noun Phrases (NPs), Verb Phrases (VPs), Prepositional phrases (PPs), Adverbial Phrases (ADVPs), and Adjectival Phrases (APs).

- Sentences have both linear sequences of words; a hierarchical structure with phrases nested in phrases and resulted in dominance and precedence relationships.

\subsection{Research problem}

Different researchers (e.g. Haileluel, 1991; Hetzron, 1966; Palmer, 1959; Tadesse 1984; Yaregal, 2007) studied Awgni language. On the other hand, to the responsiveness of the researcher, none of these studies investigated syntactic representations found in Awgni structural based sentences. As a result, college students, teachers, researchers, and other Awgni language users face difficulties in the case of understanding lexical and phrasal categories, head, complement, adjunct, and specifier, syntactic relations and other sources of recursion structures within the sentence. They were incompetent to analyze syntactic structures found in Awgni sentences in a systematic and explicit ways. Therefore, the inspiration of this article is intend to fill the gap through analyzing syntactic structures found in Awgni sentences based on a form.

\subsection{Objective of the study}

The general objective of this article is to undertake the systematic examination of syntactic structures found in structural based Awgni sentence. Accordingly, the specific purposes of the projected study are:

(1) To analyze syntactic representations found in Awgni sentences.

(2)To examine syntactic relations found in Awgni sentence.

\subsection{Literature review}

Syntax is the study of the rules governing the way words are combined to form sentences. In other words, it studies the structure of sentences. Syntax is the study of the principles and process by which sentences were constructed in particular languages and concerned with the ways in which words combined to form phrases and sentences (Chomsky, 1966; Radford, 1997).

The most reliable criterion used in judging the lexical category of words is meaning, its syntactic function or distributional possibilities by taking account of behavior in sentence (Baye, 1986; Chomsky, 1957, 1965; Kim, 2007; Miller, 2002; O’Dwyer, 2000). Therefore, lexical categories found in Awgni language include Noun, Verb, Adjective, Adverb, and Preposition. Phrases are generally constituents that are built up around a particular word. They are group of words that functions as a single unit in syntactic structure of sentence (Borsley, 1996). Phrases can be classified into Noun Phrase (NP), Verb Phrase (VP), Prepositional Phrase (PP), Adverbial Phrase (Adv P), and Adjectival Phrase (AP). The head of phrase can be modified by any construction or words. Accordingly, languages share certain structural similarities in X-Bar sentence structure formation (Carnie, 2002; Chomsky, 1970; Jackendoff, 1977; Jacobs, 1995; McCawley, 1988). Thus, Awgni like other languages shares certain universal phrasal categorical patterns to the way tree diagrams organized symbolically as: S (Sentence), NP (Noun Phrase), N'(recursive), VP (Verb Phrase), V'(recursive), PP 
(Prepositional Phrase), AP (Adjective Phrase), N (Noun), V (Verb), P (Preposition), and A (Adjective) (Bach, 1974; Borsley, 1991; Burton, 1997; Radford, 1988).

Sentences are the basic unit of syntactic analysis, which is easier to see the parts of (press) and subparts (parts of speech) of the sentence in a tree (Bornstein, 1977). Similarly, x-bar trees are easier to read and enabled to see at a glance the hierarchical structures of the given sentences (Finch, 1998). Indeed, many linguists (Carnies, 2001; Chomsky, 1970; Jackendoff, 1977; Radford, 1997) assume that all XPs, where XP stands for any of NP, PP, VP, or ADP, have three levels of structure. The basic three-level X-bar schema can be displayed as in:

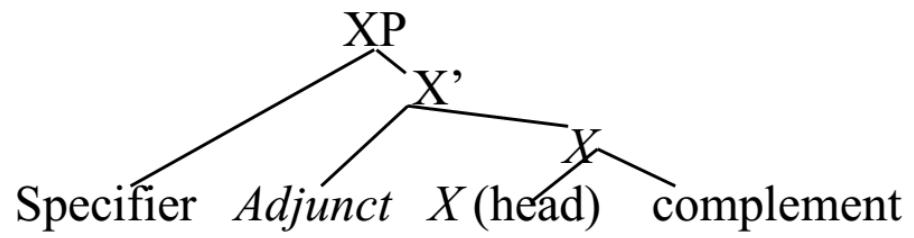

SOV arrangement of Awgni and other syntactic patterns do not allow applying this Xbar convention as it is. Therefore, the subsequent symmetrical $\mathrm{X}$-bar analysis was newly developed. In this way, the study formulates different sets of rules for different phrasal categories. $\mathrm{X}$-bar analysis in Awgni sentence structure has been applied to NP, VP, AP, ADVP and PP. Accordingly, phrase structure rules are illustrated by the means of tree diagram or phrase markers, which show the structure of the sentence (Bornstein, 1977). Phrase structure rules interpreted as an instruction to rewrite or expand the symbol on the left of the arrows as the sequence on the right as in:

$$
\begin{aligned}
& \mathrm{S} \rightarrow \mathrm{NP}, \mathrm{VP} \\
& \mathrm{NP} \rightarrow\left(\mathrm{S}^{\prime}\right),(\mathrm{Spec}),(\mathrm{NP}),(\mathrm{pp}),(\mathrm{Ad}), \mathrm{N} \\
& \mathrm{VP} \rightarrow\left(\mathrm{S}^{\prime}\right),(\mathrm{Spec}),(\mathrm{PP}),(\mathrm{NP}),(\mathrm{Ad}), \mathrm{V} \\
& \mathrm{AP} \rightarrow(\mathrm{Spec}),(\mathrm{PP}),(\mathrm{NP}), \mathrm{A} \\
& \mathrm{PP} \rightarrow\left(\mathrm{S}^{\prime}\right),(\mathrm{PP}),(\mathrm{VP}),(\mathrm{NP}),(\mathrm{AP}), \mathrm{P} \\
& \mathrm{ADV} \rightarrow(\text { Spec }),(\mathrm{PP}), \mathrm{ADV}
\end{aligned}
$$

Recall that the researcher decided that N, V, A, P and ADV were heads of their phrases based on the evidence from headedness. In practice, Awgni is head-final language and its heads are located on the right of other phrasal material. Hence, the same set of rules will be applicable to all phrases thus leading to uniformity and computational efficiency in terms of efforts, time and space. Specifier, Adjusts and Complement positions in the subsequent tree are in brackets. This indicates that they are optional in x-bar tree. Every sentence structure must have obligatory heads.

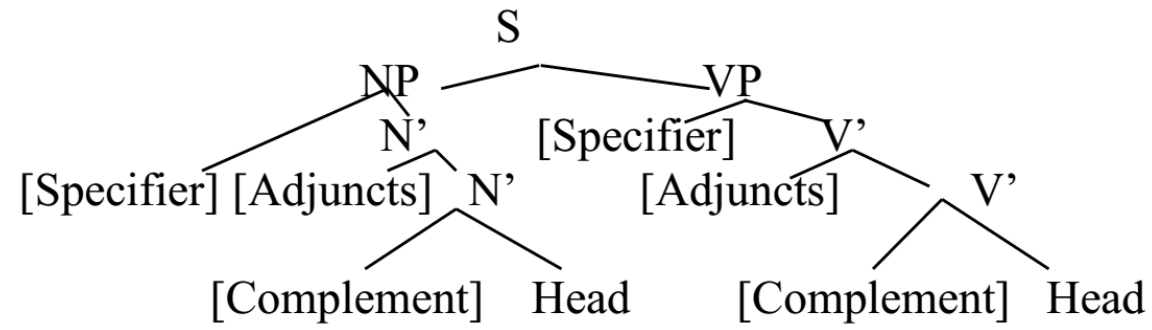

In Awgni, the head of the phrases always occurs at the right edge of the constituent in noun, verb, adjective, adverb and postposition phrases. The position of constituency is the obligatory head of each phrase types come first, and then optional complements, adjuncts and specifier may structure respectively from right to left position. Complements are phrasal categories whose objective is to provide information concerning entities and locations. Heads and 
complements are typically adjacent; in few occasions, a head verb might have two complements, adjuncts typically come after the sequence of head and complements. Adjuncts are constituents that tell us more about the how, when, where or why of the activity or situation expressed by the sentences they occur in. Adjuncts can be Verb Phrase, Adjective Phrase, Adverb Phrases, Prepositional Phrases, and Noun Phrases, independent clauses and small clauses. Most obviously, complement types structured in the tree include Noun Phrases, Adjective Phrases, and Prepositional Phrases (Chametzky, 1996).

The meaning of the given head can be more precise by specifier, and its appearance in phrase structures is not obligatory. Syntactically, it can mark a given phrase boundary and it occurs at the left side of the actual sentence tree structure. As a result, its position might be changed. Besides, the category of the specifier differs depending on the type of the head. It is, in fact, not so straightforward to find a case where all four terms head, complement, modifier and specifier syntactically filled. X-bar trees provide a precise way of defining syntactic relation. Relations between any given pair of nodes contained in the same p-marker are dominance and precedence (Bornstein, 1977; Carnie, 1995; Radford, 1981).

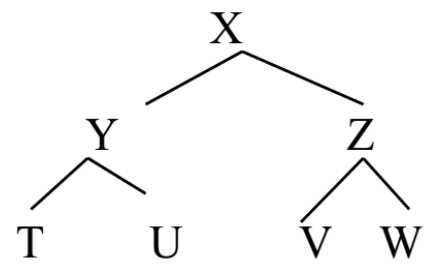

The relationships between $\mathrm{X}, \mathrm{Y}$ and $\mathrm{Z}$ are the same, except that $\mathrm{X}$ dominates $\mathrm{Y}$ and $\mathrm{Z}$, but it also dominates T, U, V and W. Thus, X exhaustively dominates a set of nodes (T, U, and V, $\mathrm{W}$ ), provided it immediately dominate all the members of the set. To distinguish the dominance relation, $\mathrm{X}$ dominates all the nodes below it, but immediately dominates only Y and Z. Using family terminology, $\mathrm{X}$ is the mother of $\mathrm{Y}$ and $\mathrm{Z}$, and, conversely, that $\mathrm{Y}$ and $\mathrm{Z}$ are the daughters of $\mathrm{X}$. Moreover, $\mathrm{Y}$ and $\mathrm{Z}$ are sisters of each other. Corresponding to the terminology concerning dominance, $\mathrm{T}$ immediately precedes $\mathrm{U}$, but only precedes $\mathrm{V}$ and $\mathrm{W}$. Constituent $\mathrm{Y}$ is a constituent of $\mathrm{X}$ if and only if $\mathrm{X}$ dominates $\mathrm{Y}$. Thus, in the above tree all of $\mathrm{Y}, \mathrm{Z}, \mathrm{T}, \mathrm{U}, \mathrm{V}$ and $\mathrm{W}$ are constituents of $\mathrm{X}$. Nodes $\mathrm{T}$ and $\mathrm{U}$ make up the constituent $\mathrm{Y}$, and that $\mathrm{V}$ and $\mathrm{W}$ make up the constituent $\mathrm{Z}$. In the case of immediate constituents, $Y$ is an immediate constituent of $X$ if and only if $X$ immediately dominates Y (Baltin \& Anthony, 1989).

The sentence is grammatically the uppermost linguistic sequence made up of one independent or super ordinate clause with a subject and a predicate or two or more closely related clauses (Downing \& Locke, 2006). Similarly, Finch (2005) recognized sentences as grammatically complete and semantically independent units of language capable of standing on their own. Complete sentences made up of essential grammatical element like the subject and finite verb not preceded by any word making it dependent on some other group of words (Finch, 2005; Millward, 1983; Nigel, 1990).

Thus, structural classification of sentence was determination of sentence types based on the grammatical construction of sentences in terms of their forms, forming, constituents' combination, or causal relationship, the number and types of classes they contain as being discussed in the next subsection.

Simple sentences have one independent clause with no subordinate clauses (Bolaji \& Alabi, 1994; Demirezen, 1998; Jackson, 1982). Due to this, they have a single subject and predicate by telling only one obsession, though, and have merely one verb, and contain just an independent (main) clause (Aarts \& Aarts, 1988). In the part of writing simple sentences were begun with a capital letter and ending by means of a period, through three dots, with a question mark, or an exclamation point (Baugh, 1993; Teschner \& Evans, 2007). 
The complete and educational explanations on compound sentences were sentences consisting of at least two clauses, each of which separated off into their own independent clauses and independent sentences (Teschner \& Evans, 2007). These types of sentences were formed by joining or linking two or more basic or non-basic, simple sentences with the aid of coordinating conjunctions or coordinators like and, but, or depending on the association between the jointed or synchronized simple sentences (Aremo, 2004; Verspoor \& Sauter, 2000). This linking could be achieved by a semi-colon; a semicolon followed by a connecting adverb; a coordinating conjunction often preceded by a comma; correlative conjunctions; tag questions; no conjunctions; and both coordinate conjunctions and conjunctive adverbs at the same time.

Complex sentences have the main clauses and two or more subordinate clauses formed through the process of subordination. The main clauses of the complex sentence were the major, super ordinate or independent clauses because they could stand on their own. The minor clauses introduced by subordinates like because, although, until, unless, etc. were the subordinate or dependent clauses because they cannot stand on their own to express a complete thought or ideas. The compound-complex sentences were a grouping of the compound and the complex sentence patterns (Finch, 2005).

\section{Methodology}

Descriptive research design was employed in this study. Through purposive sampling, thirteen sentences were selected. Based on the importance, the structure of sentence category, the layout, the length of data, types, meaning and structural simplicity as simple to display, easy to understand anticipated data were chosen. Seven informants (three females and four males) were interviewed to crosscheck the data about sentence types.

\section{Results}

The structural categorization of syntactic structure of simple, compound, compoundcomplex, and complex sentence found in Awgni was analyzed in succeeding sections.

\subsection{Simple sentences}

As a rule, the arrangement or sequences of sentence components in Awgni are subject, object, and verb. Thus, simple sentence in Awgni is a sentence that consists of just one independent clause. In this regard an independent clause can stand alone as a sentence. Parts of a simple sentence that contains subject and verb and constitute that complete thoughts were independent clause as in (1):

(1) An Awgne ïnkane

I Awgni like

'I like Awgni'

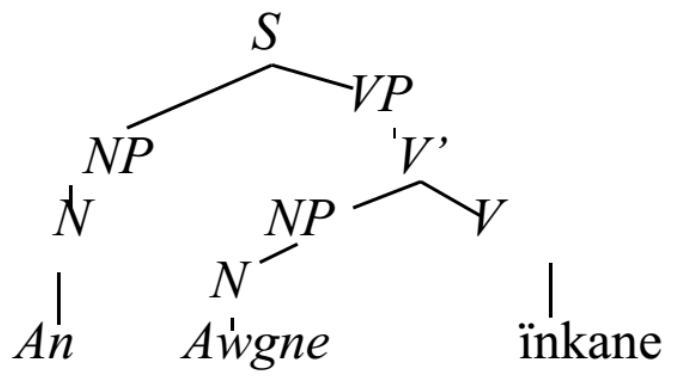


The above (1) simple sentence structure conveys a complete thought. The subject of the sentence is the Noun Phrase An, and the verb is inkane. The object Awgne is the complement that conveys the understanding of what the subject likes. On the face of it, S node immediately dominates NP and VP. Thus, NP precede VP node. As a result, S node is the mother of two constituents NP and VP. These in turn are daughters of S node; all terminal nodes (N, N, and V) are sisters to each other.

(2) Kisi bǐštanšo ïnzene

The priest to the church walking

'The priest walking to the church'

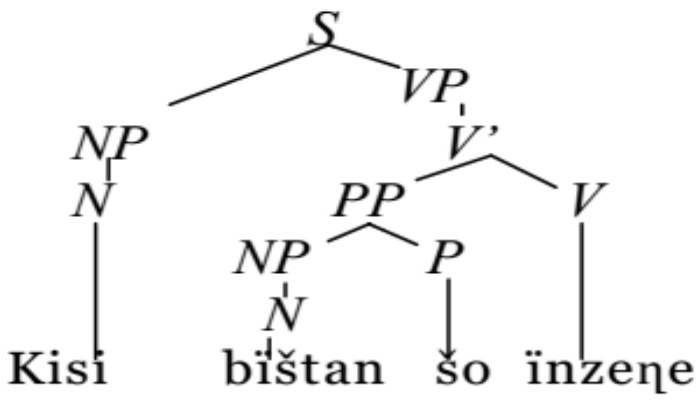

The preceding (2) simple sentence structure consists of merely single independent clause, which has a Noun Phrase kisi and a Verb Phrase bï̌tanšo ïnzene with a finite verb. In Awgni grammar, a finite verb is a form of a verb that shows agreement with a subject and is marked for tense. When a verb has a subject and a tense, it can be referred to as a finite verb. In the case of head inzene, no person or thing receives the action. There is no object of the verb. Since, the verb shows movement, it immediately take Prepositional Phrase complement yïnšo. It appears that, S node immediately dominates NP and VP. Thus, NP precede VP node. As a result, S node is the mother of two constituents NP and VP. These in turn are daughters of S node; all terminal nodes (N, N, P and V) are sisters to each other.

(3) Mamu sta Agalu sigarawa jewuna Mamu and Agalu the cigarette bought 'Mamu and Agalu bought the cigarette'

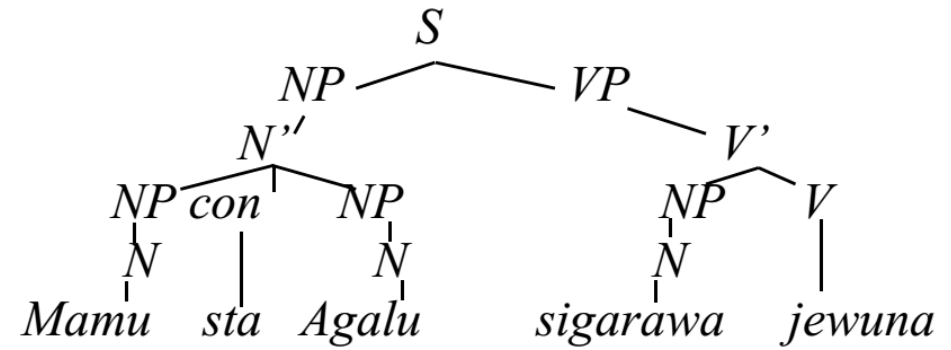

This (3) simple sentence has compound subject: Mamu and Agalu. The conjunction sta conjoins these Nouns. The Verb in the given structure is jewuna. Here the top of the tree depicts the subject Mamu, the predicate jewuna and a third item, the object sigarawa, which is the complement. Sigarawa refers to the entities on which the act of buying performed. The subject Mamu and the complement sigarawa are the two arguments of the predicate jewe (i.e. the two entities involved in the act of buying). Regarding relationship between syntactic representations exits in, $\mathrm{S}$ node immediately dominates NP and VP. Thus, NP precede VP node. As a result, $\mathrm{S}$ node is the mother of two constituents (NP and VP). These in turn are daughters of S node; every single terminal node ( N, N, N and V) are sisters to each other. 
(4) Ligisimi aqi tuše xuwe A tall man the bread east's

A tall man east's the bread'

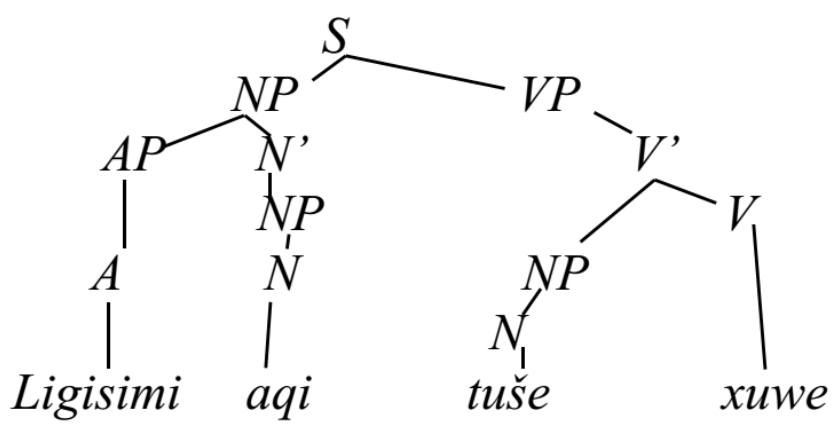

Tree notation (4) has the subject ligisimi aqi, the object tuše and the verb xuwe. Tuše is the complement of xuwe. This is because; xuwe passes over from the subject (aqi) and the object (tuše). Now, the analysis is claiming that tuše xuwe is VP which itself contains another NP tuše, and a verb xuwe. It appears that, S node immediately dominates NP and VP. Thus, NP precede VP node. For that reason, $\mathrm{S}$ node is the mother of two constituents NP and VP. These in turn are daughters of S node. Apparently, NP immediately dominates AP and N'; VP node also immediately dominates NP and V. Thus, all terminal nodes (A, N, N and V) are sisters to each other. It possibly will also contain other types of elements.

\subsection{Compound sentences}

In Awgni grammar, a compound sentence is two (or more) simple sentences connected through a conjunction or an appropriate mark of punctuation. Both sides of a compound sentence are inclusive on their own, but more significant when connected. They are made up of at least two independent clauses, expressing intimately related ideas of equal or the same meaning that are joined together using a comma and a conjunction (sta/and, yaxesgu/however or axuki/or) a semicolon and a conjunctive adverb, or just a semicolon.

(5) Mamu baburo mande; yaxesgu babur yintayaki Mamu the train waited; but the train was late' 'Mamu waited for the train, but the train was late'

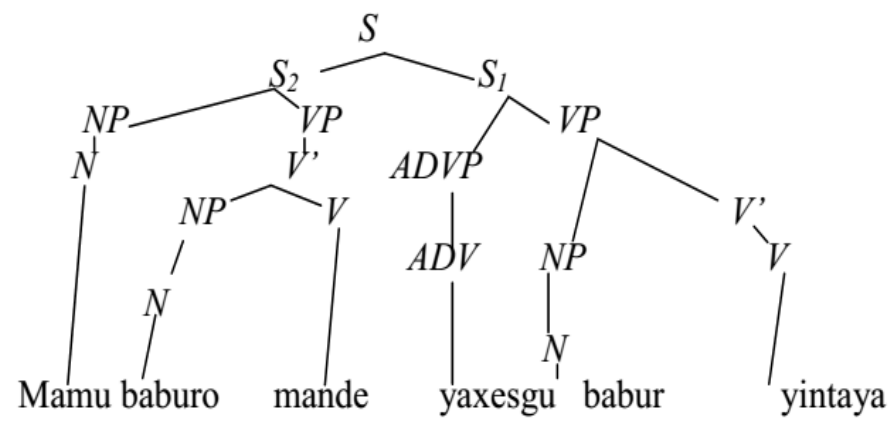


Mamu baburo mande; yaxesgu babur yintayaki is a compound sentence which contains two independent clauses such as Mamu baburo mande and babur yintayaki. Conjunctive adverbs yaxesgu was used to join two independent clauses together. As displayed in $\mathrm{x}$-bar tree, $\mathrm{S}$ node is structured into two sentences: $\mathrm{S}_{2}$ Mamu baburo mande and $\mathrm{S}_{1}$ yaxesgu babur yintayaki. These nodes are the immediate complement for the mother node (S). Apparently, $S_{2}$ precede $S_{1}$ and they in turn are internal nodes. Each node under the tree has their linear and hierarchical relationship. Yaxesgu used to join two simple sentence structures to make compound $\left(\mathrm{S}_{2}\right.$ and $\left.\mathrm{S}_{1}\right)$.

(6) Makinawa jepa; yaxesgu kibra

The car I have bought, however expensive

'I have bought the car, however it is expensive'

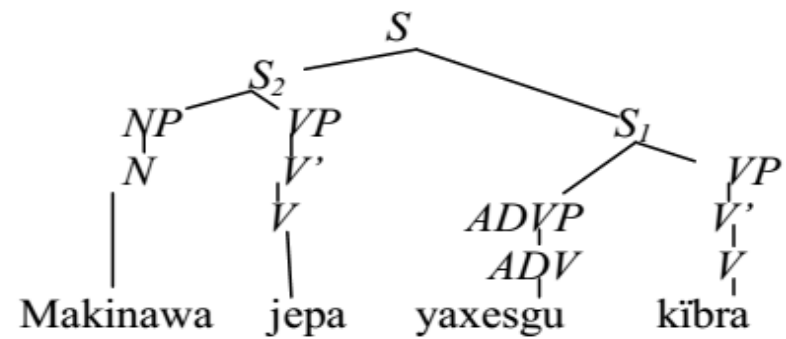

Compound sentences in (6) require conjunction yaxesgu. In that case, syntactic structure of makinawa jepa, yaxesgu kïbra consists of, S2 makinawa jepa and S1, yaxesgu kïbra. In terms of relation, the mother node $\mathrm{S}$ immediately dominates $\mathrm{S} 2$ and $\mathrm{S} 1$. Thus, S2 precedes $\mathrm{S} 1$ node. S2 more to the point immediately dominates NP and the VP. S1 in turn dominates ADVP and $\mathrm{V}$.

\subsection{Complex sentences}

Complex sentences in Awgni consist of only one independent and at least one dependent clause, and often more than one dependent clause. Many instances of conjoining constituents other than clauses best regarded as a version of conjoined clauses. When complex sentence structures analyzed, it is better to identify these structures by isolating words belonging to the Noun Phrase (NP) and the Verb Phrase (VP). The Verb Phrase often contains other words, phrases, or clauses that play further distinctive roles within the sentence. When this occurs, the structure is then broken down into the Noun Phrase and Verb Phrase themselves and any other words, phrases or clauses as in:

(7) Naka yïntux Nigusie lïgda yaxa Today came Nigusie handsome became 'Nigusie who came today became handsome'

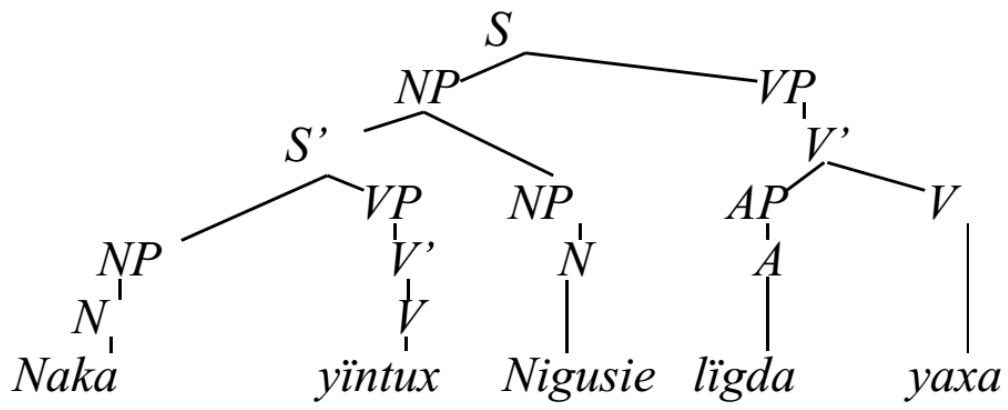


According to (7), the sentence structure Naka yïntux Nigusie lïgda yaxa is broken down into Noun Phrase Naka yïntux Nigusie and Verb Phrase lïgda yaxa. The Noun Phrase on the left hand consists of dependent clause modifier (naka yintux) and Noun Phrase (Nigusie). At the right side of the tree, Verb Phrase conjoined with Adjective Phrase ligda and the verb yaxa. Here $\mathrm{S}$ is the mother of two constituent NP and VP. These two constituents in turn are daughters of S node. Furthermore, S' node actually occurs the left of NP node on the printed page. The two are linked by a branch (solid line) indicates that the NP node in fact immediately dominates S' and NP. S' also immediately dominates NP and VP. Recursion level of V' in turn immediately dominates AP and V.

(8) Agalu gïbitux beru kari duntuxa

Agalu made metal knife broken

'The metal knife which Agalu made was broken'

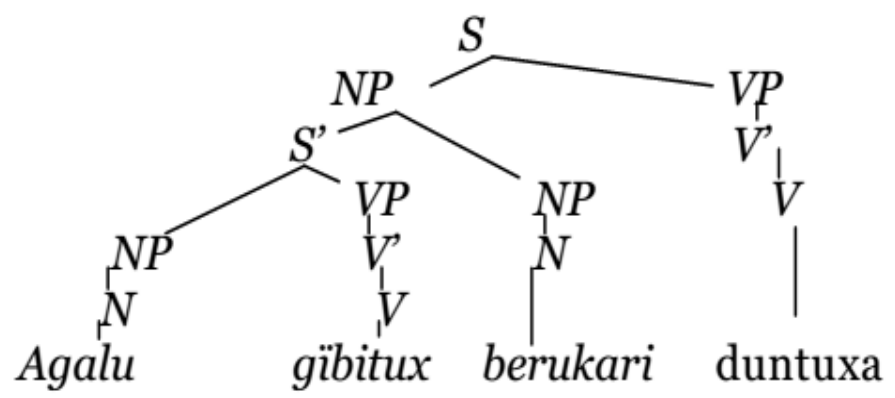

The syntactic structure in (8) displayed that Agalu gïbitux beru kari is the Noun Phrase. Dependent clause Agalu gïbitux comes first. It modifies the Noun Phrase beru kari. The dependent clause Agalu gïbitux supports independent clause. The main clause comprises the subject Agalu, the Verbal predicate duntuxa and the complement clause Agalu gïbitux. This clause in turn comprises the subject Agalu and the Verbal predicate duntuxa. At this point, $\mathrm{S}$ is the mother of two constituent NP and VP. These two constituents in turn are daughters of S node and N, V, N, and $\mathrm{V}$ are sisters of each other. The two nodes linked by a solid line indicates that the NP node in fact immediately dominates S' and NP. S' also immediately dominates NP and VP.

(9) yïn gudya ganbistayasu axyïs feresxo House well was not constructed as destroyed 'As the house wasn't well constructed, it was destroyed'

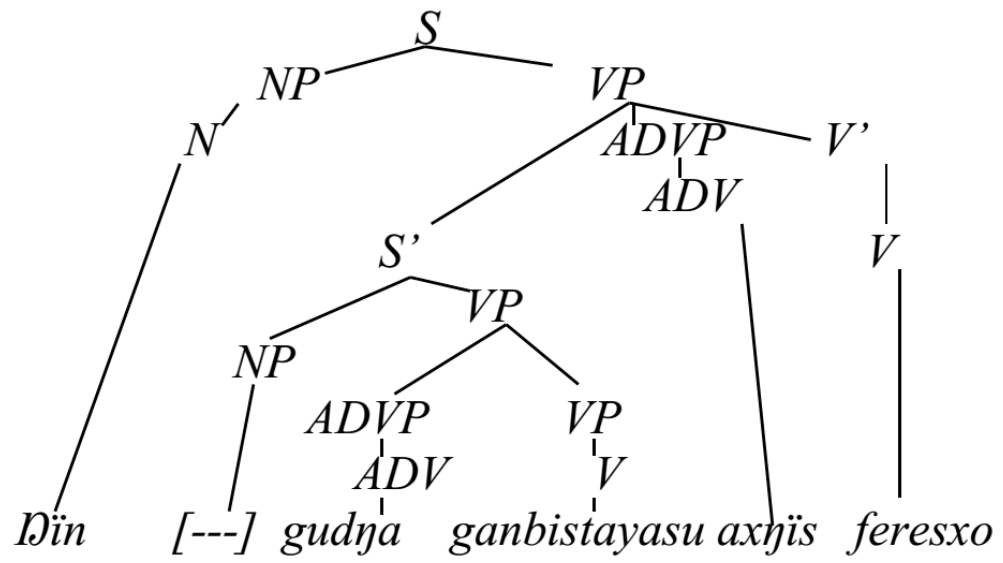


Structure (9) puts on view that dependent and independent clauses are conjoining in the tree diagram. Gudya ganbistayasu is a dependent clause. The second merge feresxo is the simple sentence that it contains the subject $\eta \ddot{n}$ and the verb feresxo. However, $\eta \ddot{n}$ serves as subject for dependent (gudya ganbistayasu) and independent clauses (feresxo). The subject yïn is the Noun Phrase (NP) ganbistayasu is the Verb Phrase (VP). Axyïs is also an Adverb (ADV), which serves as a subordinating conjunction. In terms of relations, the mother node S immediately dominates its daughters NP and VP. Consequently, NP preceded VP. Thus, S exhaustively dominates all the other nodes in the tree, however it does not immediately dominate any of the other nodes for the reason that other nodes (S', VP, ADVP, and V') interfere. To be rigorous, the relation of motherhood is one of immediate dominance not dominance.

(10) Koleču jïme jïmyu fay kičyuxa

Koleč music playing interest has been achieved

'Koleč's interest in playing music has been achieved'

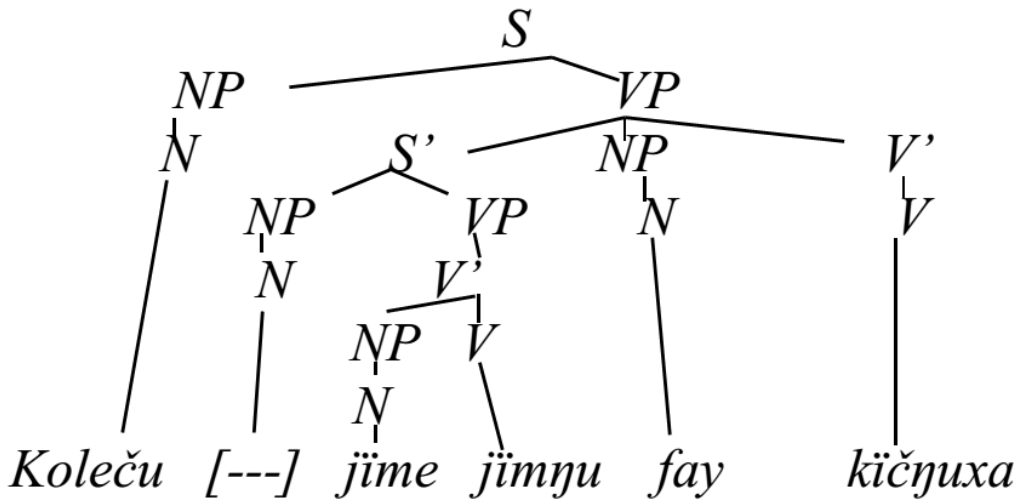

According to (10), both dependent (Koleču jïme jümpu) and the independent (fay kï̌nuxa) clauses are necessary to make a complete meaning. The main clause (kïčnuxa) does not make sense on its own, and it requires the dependent clause (Koleču jïme jïmpu) to complete its meaning. While their relation between syntactic representations examined, NP precedes VP and they are constituents of S. S node immediately dominates these daughters simultaneously. VP node in turn has S', NP and V' constituents and immediately dominates these nodes. Furthermore S' node immediately dominates NP and VP. Besides VP node immediately dominates NP and V.

(11) Molla mïntamïrdes xïsaw buzi aqi ïste Molla Mintamir than fat man say 'It was said that Molla is fatter than Mintamir'

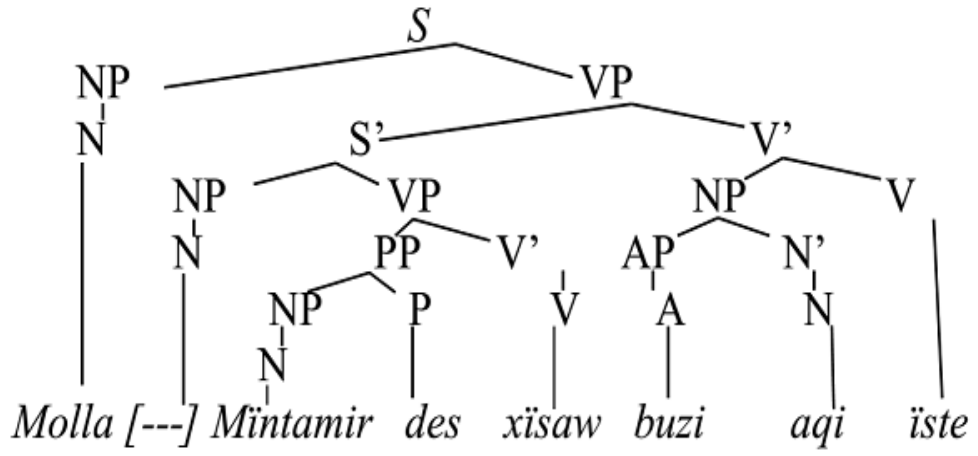

The above-mentioned tree tells us that the overall expression Molla mïntamïrdes xïsaw buzi aqi ïste is sentence structure. Its head is the verb ïste, and structured with complement Noun Phrase (NP) buzi aqi. On the other hand, the dependent clause (S') Mïntamïrdes xïsaw 
modifies the head verb (iste). The subject of the given sentence is Molla and its predicate is ïste. Furthermore, the mother node S immediately dominates its daughters NP and VP. As a result, NP preceded VP. Therefore, NP and VP are constituents of S. VP immediately dominate S' and V'. Likewise, S immediately dominates NP, and VP; VP node immediately dominates PP and V'. PP in turn immediately dominates $\mathrm{NP}$ and $\mathrm{P}$. V' immediately dominates $\mathrm{NP}$ and $\mathrm{V} ; \mathrm{NP}$ also immediately dominates AP and N'. Every terminal node is sisters to each other.

\subsection{Compound-complex sentences}

Awgni compound complex sentences made from two independent clauses and one or more dependent clauses as in (12):

(12) Sïr zikokus, gïsens instaštuxa, ïnaxns gsenkawa jïfiste Child when I was by a dog attacked thus dogs afraid 'When I was a child, I was attacked by a dog, thus, I am afraid of dogs'

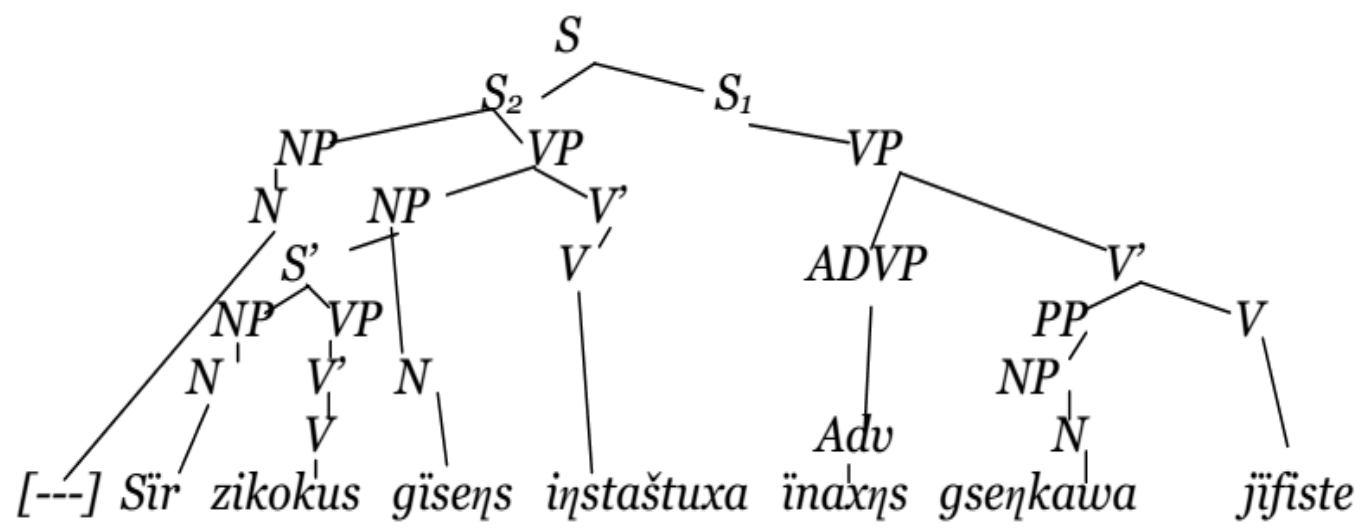

As stated in the above tree sïr zikokus, gïsens instaštuxa, ïnaxns gsenkawa j̈̈fiste is a compound-complex sentence. It is the combination of two independent clauses gïsens instaštuxa and ïnaxns gsenkawa j̈̈fiste. The tree also structured with one dependent clause sïr zikokus. A single $\mathrm{S}$ node, exhaustive dominance holds between a set of daughter $\left(\mathrm{S}_{2}\right.$ and $\left.\mathrm{S}_{1}\right)$ nodes and their mother node (S) exhaustively dominates a set of nodes $\mathrm{S}_{2}, \mathrm{~S}_{1}$, and their constituents. On the other hand, since $S_{2}$ precedes $S_{1}$ the linear precedence relation(s) between the daughter nodes could easily be expressing.

\section{Discussion}

The study was attempted to assess systematic examination of syntactic representations found in structural based Awgni sentence structures. Lexical categories found in Awgni sentences include Noun (N), Adjective (A), Verb (V), Adverb (ADV), and Preposition (P), though more categories were relevant to Awgni language sentences. Henceforth, Awgni Phrases under sentence structure were classified by the type of the head they take as: Prepositional Phrase (PP), Noun Phrase (NP), Verb Phrase (VP), Adjective Phrase (AP) and Adverb Phrase (ADVP). Since simple, compound, complex and compound-complex sentence were differed in terms forms, forming, constituents' combination, or causal relationship; the number and types of syntactic phrasal categorical representations were somehow dissimilar. The finding further examined the features of speakers' syntactic understanding like the linear order of the words in the sentence, the groupings of words into syntactic categories and the hierarchical structure of the syntactic 
categorical representations. Thus, overall syntactic relations discussed about syntactic representations established in Awgni sentence structures were summarized based on the foundation of Bornstein (1977), Carnie (1995) and Radford (1981) as in:

(13) Naka tintut Alemitu ligda taxuxa Today came Alemitu beautiful became 'Alemitu who came today became beautiful'

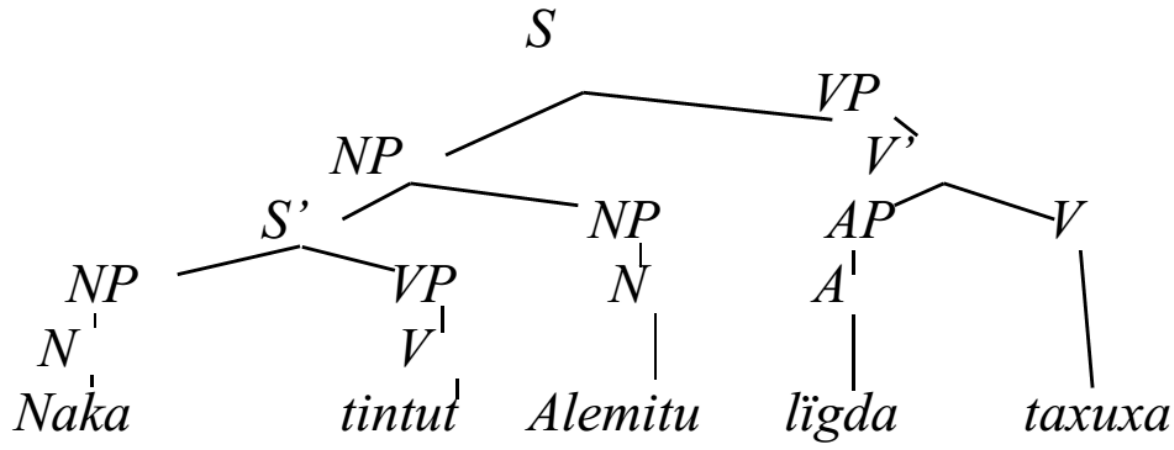

Like research findings (Bach, 1974; Borsley, 1991; Burton, 1997; Radford, 1988) showed that in the above complex sentence structure, the topmost node $\mathrm{S}$ is the root of the tree; it contains immediately or non-immediately all the other nodes. The clause (S) was built from NP that immediately proceeded by VP. In the case of hierarchical and linear relation, $\mathrm{S}$ node immediately dominates the Noun Phrase (NP) and the Verb Phrase (VP). Then, S is the mother of NP and VP and thus, two nodes are daughters of sentence structure. Likewise, structures such as S, S', NP, and V' are internal nodes where; N, V, N, A and V are sisters of each other.

In experimented tree diagrams, each phrase contained a head and possibly, but not necessarily, one or more modifiers. Complements, adjuncts and specifier were optional; complements were typically obligatory and always mentioned in the lexical entries for verbs. Many collocation restrictions applied to heads. Heads and complements were typically adjacent; where a head might have two or more complements, adjuncts typically come before the sequence of head and complements.

\section{Conclusion}

The results showed that simple, compound, complex and compound complex sentences shared linear arrangements of the words in sentence, the groupings of words into syntactic categories and the hierarchical structure of the syntactic categories in the given $\mathrm{x}$-bar tree. These sentences were also hierarchically structured into successively larger set of constituents, with each constituent belonging to a given categories like A,N, V,P,AD and resultant phrasal categories for instance NP, VP, PP, AP and ADVP.

Sentence types have an internal association that could characterize using the tree diagram. Notable features of constituent structure being drawing in tree were heads, complements, modifiers, and specifier. There were two types of relations existed between every particular couple of nodes contained in similar phrase markers are precedence or dominance. Precedence relation comes into view while one node immediately occurred to the left side of another node in a given phrase marker. The other type of relation occurred among nodes in the same phrase marker was dominance. The node dominated the other just when it occurred higher up in the tree than the initial node, and connected to the first node by continuous set of solid lines. One node was immediately dominating the other if it was the next higher node up in the tree, and connected to the other node by a single branch. Moreover, nodes can have mothers (dominating 
other node), daughters node (immediately dominated by that other node) and sister nodes (immediately dominated by same node. However, simple, compound, complex and compoundcomplex sentence were coming in a diversity of shape, method, and size utterances. These sentences were differed in terms forms, forming, constituents' combination, or causal relationship, the number and types of classes they contain. Due to these features, the nature of syntactic representations found in simple, compound, complex and compound-complex sentence were to some extent syntactically dissimilar.

\section{Acknowledgements}

I would like to acknowledge my respondents who delivered valuable data and College lecturers who participate in editing (Alemnesh, Desalegn, Muluken, Wudu, and Yibeltal). In this case there were no funding organizations evolved in this study.

This research did not receive any specific grant from funding agencies in the public commercial, or not-for-profit sectors.

The author declares no competing interests.

\section{References}

Arts, F., \& Aarts, J. (1988). English syntactic structures. Oxford: Pergamon Press.

Aremo, B. (2004). An introduction to English sentences (I \& II). Ibadan: Scribo Publication Ltd.

Bach, E. (1974). Syntactic theory. New York: Holt, Rinehart and Winston.

Baugh, L. S. (1993). Essentials of English grammar: A practical guide to the mastery of English. Lincolnwood (Chicago), Illinois: Contemporary Publishing Group, Inc.

Bay, Y. (1986). Amharic grammar. Addis Ababa: E.M.P.D.A.

Bolaji, E. B., \& Alabi, V. A. (Ed.) (1994). The principles practice of communication. Ilorin: I.G.S. Publication

Bornstein, D. (1977). An introduction to transformational grammar. Cambridge, Massachusetts: Winthrop Publishers, Inc.

Borsley, B. (1991). Syntactic theory: A unified approach. Cambridge: Blackwell.

Borsley, R. (1996). Modern phrase structure grammar. Oxford: Blackwell. ${ }^{1}$

Burton-Roberts, N. (1997). Analyzing sentences: An introduction to English syntax. $2^{\text {nd }}$ Edition. Longman.

Carnie, A. (1995). Head movement and non-verbal predication. Ph.D. Dissertation, MIT Press.

Carnie, A. (2001). Syntax. Oxford: Blackwell.

Carnie, A. (2002). Syntax: A generative introduction. Oxford: Blackwell.

Chametzky, R. (1996). A theory of phrase markers and the extended base. Albany: SUNY Press.

Demirezen, M. (1998). From sentence to paragraph structure. Ankara: Adım Publications.

Chomsky, N. (1957). Syntactic structures. The Hague: Mouton.

Chomsky, N. (1965). Aspects of the theory of syntax. Cambridge, Mass.: MIT Press.

${ }^{1}$ This book presents a different view of phrase structure (from the HPSG perspective). 
Berhanu Asaye Agajie - Syntactic Structure of Awgni Sentences Based on Form

Chomsky, N. (1966). Syntactic structures. Paris: Mouton \& Co.

Chomsky, N (1970). Remarks on nominalization. In R. Jacobs \& P. Rosenbaum (Eds.), Readings in English transformational grammar. Waltham: Ginn. 184-221.

Downing, A., \& Locke, P. (2006). English grammar: A university course (2 ${ }^{\text {nded}}$ ). London: Routledge.

Finch, G. (1998). How to study linguistics. London: Macmillan.

Finch, G. (2005). Key concepts in language and linguistics. New York: Palgrave Macmillan.

Haileluel, Y. (1991). Verb complementation in Awgni. MA Thesis. Addis Ababa University.

Hetzron, R. (1966). The verbal system of Agau. Phd Dissertation. Lo Angeles: University and California.

Hetzron, R. (1969). The verbal system of Southern Agaw. University of California Press. Berkeley.

Jackendoff, R. (1977). X-bar syntax: A theory of phrase structure. Cambridge: MIT Press.

Jackson, H. (1982). Analyzing Englishman introduction to descriptive linguistics. Oxford: Pergamon Press.

Jacobs, R. (1995). English syntax: A grammar for English language professionals. Oxford University Press.

Kim, J., \& Peter, S. (2007). English syntax: An introduction. Center for the Study of Language and Information.

Lodge, K. (2009). Fundamental concepts in phonology. Edinburgh University Press.

Melakneh, M. (1991). Themes and motifs in Southern Agaw folktales. M.A. Thesis. Addis Ababa University.

Miller, J. (2002). An introduction to English syntax. Edinburgh: Edinburgh University Press.

Millward, C. (1983). Handbookfor writers. New York: Holt, Rinehart, and Winston

Nigel, K. (1990). Students writers guide: An A-Z of writing and language. Leckhampton: Stanley Thornes (Pub) Ltd.

O'Dwyer, B. (2000). Modern English structure: Form, function and position. Canada: Broadview Press.

Palmer, F. R. (1959). The verb classes of Agaw (Awiya). Mitteilungen des Instituts fuer Orientforschung, 7 , 270-297.

Radford, A. (1988). Transformational grammar: A first course. Cambridge: Cambridge University Press.

Radford, A. (1997). Syntactic theory and the structure of English. New York and Cambridge: Cambridge University Press. Richter.

Tadesse, M. (1984). The noun phrase in Awgni. M.A. Thesis. Addis Ababa University.

Tadesse, T. (1988). Process of ethnic interaction and integration in Ethiopian history: The case of Agua Proceedings of the $9^{\text {th }}$ International Coverage of Ethiopian Studies. Moscow: Nauka Publisher. Vol. 6, pp. 192-206.

Teferi, G. (2000). An analysis of Awngi proverbs. M.A. Thesis. Addis Ababa University.

Teschner, R., \& Evans, E. (2007). Analyzing the grammar of English (3 ${ }^{\text {rd }}$ Ed.). Washington, DC: Georgetown University Press.

Verspoor, M., \& Sauter, K. (2000). English sentence analysis: An introductory course. Amsterdam: John Benjamin Publishing Co.

Yaregal, A. (2007). Case in Awngi. M.A. Thesis. Addis Ababa University. 


\section{Appendix}

\section{Awgni Phonology}

Phonology studies how languages or dialects systematically organize their sounds (or signs, in sign languages). The term also refers to the sound system of any particular language variety (Lodge, 2009). Thus, Awgni Phonology is the study of the patterns of sounds in the language. Put more properly, phonology is the study of the categorical organization of speech sounds in languages; how speech sounds are organized in the mind and used to convey meaning. In order to understand, syntactic transcriptions, it is important to locate few points about Awgni vowels and consonants.

\section{Vowels}

\begin{tabular}{|c|c|c|c|}
\hline & Front & Central & Back \\
\hline Close & $\mathrm{i}$ & $\ddot{\mathrm{i}}$ & $\mathrm{u}$ \\
\hline Open & $\mathrm{e}$ & $\mathrm{a}$ & $\mathrm{o}$ \\
\hline
\end{tabular}

The central vowel / $\ddot{i}$ / is the default epenthetic vowel of the language and almost totally predictable in its occurrence. Likewise, /æ/, normally an allophone of /a/, is fossilized in some words and might be justified as a separate phoneme.

\section{Consonants}

\begin{tabular}{|l|c|c|c|c|c|c|c|c|c|}
\hline & Bilabials & Labiodentals & Dental & Alveolar & Palatal & Velar & Labiovelar & Uvular & $\begin{array}{l}\text { Labio } \\
\text { uvular }\end{array}$ \\
\hline Plosive & $\mathrm{b}$ & & $\begin{array}{c}\mathrm{d} \\
\mathrm{t}\end{array}$ & & & $\begin{array}{c}\mathrm{k} \\
\mathrm{g}\end{array}$ & $\begin{array}{c}\mathrm{k}^{\mathrm{w}} \\
\mathrm{g}^{\mathrm{w}}\end{array}$ & $\mathrm{q}$ & $\mathrm{q}^{\mathrm{w}}$ \\
\hline Fricatives & & $\mathrm{f}$ & & $\mathrm{s}$ & $\begin{array}{c}\check{\mathrm{z}} \\
\mathrm{z}\end{array}$ & & & $\mathrm{x}$ & $\mathrm{x}^{\mathrm{w}}$ \\
\hline Affricates & & & & $\begin{array}{c}\mathrm{dz} \\
\mathrm{ts}\end{array}$ & $\begin{array}{c}\mathrm{j} \\
\check{c}\end{array}$ & & & & \\
\hline Nasal & $\mathrm{m}$ & & $\mathrm{n}$ & & & $\mathrm{n}$ & $\mathrm{\eta}^{\mathrm{w}}$ & & \\
\hline Semivowels & $\mathrm{w}$ & & & & $\mathrm{y}$ & & & & \\
\hline Lateral & & & & $\mathrm{l}$ & & & & & \\
\hline Trill & & & & $\mathrm{r}$ & & & & & \\
\hline
\end{tabular}

Tones: According to Tadesse (1984), Awgni is a tonal language. It has one dynamic and three static tones. These comprise one contour (falling) and three level tones (high, mid and low). By the same token, Palmer (1959) and Hetzron (1969) both identified three distinctive tone 
levels in Awngi: high, mid and low. The low tone, however, merely appears in word-final position on the vowel /a/. A falling tone (high-mid) appears on word-final syllables only.

Syllable: The Awngi syllable in most cases fits the maximum syllable template CVC (C standing for a consonant, $\mathrm{V}$ for a vowel). It also follows the patterns like: CV, VC, CVCVCCV, VCCCVCC, CVCC and CCVCC.

Vowel harmony: Whenever a suffix containing the [+high] vowel i is added to a stem, a productive vowel harmony process is triggered. Hetzron (1969) calls this process regressive vowel height assimilation. The vowel harmony only takes place if the underlying vowel of the last stem syllable is e. This vowel and all preceding instances of e and o will take over the feature [+high], until a different vowel is encountered. Then the vowel harmony is blocked.

Orthography: Awngi is used as Medium of Instruction from Grade 1 to 8, 9-12 and in the College level in Awi Zone. It is written with an orthography based on the Ethiopian Script. Extra fidels used for Awngi are of for the sound $\mathrm{y}$ and $\bar{\phi}$ for the sound $q$. The Fidel $\theta$ is used for ts/s, the Fidel $\mathrm{n}$ for the sound $\mathrm{X}$.

The noun: is marked for number-cum-gender (masculine, feminine or plural) and case. The nominative is unmarked for one class of nouns, or marked by -i for masculine nouns and $-\mathrm{a}$ for feminine nouns. Other cases are accusative, dative, genitive, locative, directional, ablative, commutative, comparative, invocative and translate. Hetzron also mentions adverbial as a case of Awngi, but an interpretation as a derivational marker seems to be more appropriate. Both number-cum-gender and case are marked through suffixes to the noun stems (Hetzron, 1969).

The Verb: The Awngi verbal morphology has a wealth of inflectional forms. The four main tenses are imperfective past, imperfective non-past, perfective past and perfective non-past. There are various other coordinate and subordinate forms which are all marked through suffixes to the verb stems. The following distinctions are maintained for Person: 1sg, 2sg, 3masc, 3fem, 1pl, 2pl, 3pl. Awngi verbal morphology is most economically described when it is assumed that for every verb there are four distinct stems: The first stem is for 3masc, $2 \mathrm{pl}, 3 \mathrm{pl}$. The second stem is for 1 sg only, the third stem for 2 sg and 3 fem, and the fourth stem for 1pl only. These four stems need to be noted for every verb in the lexicon and serve as the basis for all other verbal morphology. The stems remain the same throughout all verbal paradigms, and it is possible to predict the surface form of each paradigm member with these stems and the simple tense suffixes (Hetzron, 1969).

Syntax: The main verb of a sentence is always at the end. The basic word order is therefore SOV. Subordination and coordination is achieved exclusively through verbal affixation. 